\title{
KHÁOS HESIÓDICO: UM BREVE ESTUDO INTERPRETATIVO
}

\author{
Camila Aline Zanon ${ }^{1}$
}

\begin{abstract}
Resumo
Entidade primordial na Teogonia de Hesíodo, Kháos tem sido objeto de várias interpretações desde a Antiguidade. Com base em suas menções no poema e em interpretações correntes, este artigo tem como objetivo investigar seu significado e seu papel no cosmo apresentado por Hesíodo por meio do método histórico-filológico. O enfoque incidirá sobre o próprio poema, tentando-se compreender o papel de Kháos dentro de sua lógica interna.
\end{abstract}

\section{Palavras-chave}

Kháos; Teogonia; Hesíodo; cosmogonia.

\footnotetext{
1 Pós-doutoranda, bolsista FAPESP - Universidade de São Paulo, São Paulo, Brasil. Email: camila.zanon@usp.br.
}

Heródoto, Unifesp, Guarulhos, v.5, n.2 - 2020.2. p. 48-70.

DOI: $10.34024 /$ herodoto.2020.v5.12833 


\begin{abstract}
As a primordial entity in Hesiod's Theogony, Kháos has been the object of several interpretations since Antiquity. Based on its mentions in the poem and examining current interpretations, this paper aims to investigate its meaning and role in the cosmos presented by Hesiod through the historical-philological method. The focus will be on the poem itself in order to understand what Kháos represents within the poem's internal logic.
\end{abstract}

\title{
Keywords
}

Kháos; Theogony; Hesiod; cosmogony. 


\section{Introdução}

O debate acerca do significado de Kháos na Teogonia de Hesíodo já ocorria na própria Antiguidade, e na Modernidade pesquisadores também têm se dedicado a investigá-lo. ${ }^{2}$ Diante do caráter elusivo de Kháos, este artigo se constitui como um breve esforço interpretativo com o intuito de compreender o possível significado e papel dessa entidade primordial, centrando-se no próprio poema sem, contudo, desconsiderar interpretações correntes.

Antes de iniciar a análise, faz-se necessário apontar o que considero uma confusão comum causada pelo uso da palavra "caos" ao se lidar com a Teogonia de Hesíodo. Muitos classicistas que trabalham com o poema são cientes do problema suscitado pelo uso de "caos" como tradução para o Kháos teogônico, ainda assim certo uso é observado de modo que se reforça sua interpretação como "desordem". A título de exemplo, quando classicistas afirmam que Tífon/Tifeu é um "agente do caos" na Teogonia (como Détienne e Vernant, 2018: 107 e s.), quer-se dizer que Tífon é um agente contra a ordem, mais especificamente a ordem de Zeus. ${ }^{3}$ Entretanto, isso conduz leitores a pensar que Tífon é de alguma forma relacionado ao Kháos primordial, o que não é o caso: Tífon nasce da união entre Terra (Gaîa) e Tártaro e pertence a uma linhagem que não tem relação com Kháos. Na verdade, como colocado por Mondi (1989: 28), Kháos e Terra inauguram não "dois ramos" de uma mesma árvore da qual todo o cosmo hesiódico descende, mas constituem "duas árvores distintas". Assim, os descendentes de Terra, por um lado, e os de Kháos, por outro, apresentam funções diferentes na organização do cosmo no poema.

O uso da expressão "agente do caos" para Tífon pressupõe "caos" como desordem, e apesar de esse não ser o significado de Kháos na Theogonia, ele leva a confundir "Kháos", "caos" e o papel e a função de Tífon na cosmogonia apresentada no poema. A expressão "agente do caos" advém do motivo da Chaoskampf ("batalha contra o caos", em alemão), trabalhado por Hermann Gunkel numa obra de 1895 para a interpretação da literatura bíblica e mesopotâmica. ${ }^{4}$ Embora o termo em si não tenha sido usado por

\footnotetext{
2 As publicações específicas mais influentes em inglês sobre Kháos são Solmsen (1950), Bussanich (1983) e Mondi (1989). Em francês, Podbielski (1986) e Wacziarg (2001). Em português, Torrano (2012).

${ }^{3}$ A Teogonia apresenta ambas as grafias Tífon (Typháōn, 306) e Tifeu (Typhōeús, 821 e 869). ${ }^{4} \mathrm{O}$ título da publicação original é Schöpfung und Chaos in Urzeit und Endzeit (que poderia ser traduzido para o português como "Criação e Caos no Início e no Fim dos Tempos"), publicada em inglês sob o título Creation and Chaos in the Primeval Era and the Eschaton:
}

Heródoto, Unifesp, Guarulhos, v.5, n.2 - 2020.2. p. 48-70.

DOI: $10.34024 /$ herodoto.2020.v5.12833 
Gunkel, ele passou a designar a batalha contra os chamados "agentes caóticos" combatidos por seres divinos ou heróis, que representam a suposta ordem (Sonik, 2013: 1, n. 1).

Nem mesmo renomados classicistas que lidam com a Teogonia de Hesíodo escapam da armadilha de usar "caos" de modo que pode causar uma leitura equivocada ou mesmo uma confusão um tanto deletéria. ${ }^{5}$ Espero que este artigo possa ser útil a especialistas e ao público em geral, contribuindo para elucidar o caráter não caótico de Kháos na Teogonia de Hesíodo. Também intenciono propor certa compreensão dessa entidade primordial que acredito ter sido negligenciada em relação ao programa teogônico do poema, considerando seu papel como ancestral que origina a chamada "linhagem da Noite".

\section{Kháos, a primeiríssima das entidades}

Antes de narrar o nascimento dos deuses, a Teogonia de Hesíodo se inicia com um longo proêmio de 115 versos nos quais o poeta invoca as Musas e narra sua experiência no Monte Hélicon com elas, de quem ele recebeu sua canção. ${ }^{6}$ Enquanto filhas de Memória (Mnemosýne) e Zeus, elas são a autoridade divina que legitima a canção do poeta diante do público. ${ }^{7}$ Sua autoridade divina, entretanto, não implica que o conteúdo de sua canção seja verdadeiro, pois a verdade não é uma necessidade ou aspiração para as Musas: logo no início do proêmio, elas declaram saber "muita coisa enganosa falar semelhantes a genuínas", e também sabem proclamar

Religio-Historical Study of Genesis 1 and Revelation 12 (trans. K. William Whitney Jr.; Grand Rapids, MI: Eerdmans, 2006).

5 Veja-se, por exemplo, Détienne e Vernant (2008). Embora eles definam a entidade primordial na Teogonia de Hesíodo como uma "abertura escancarada e sem fundo" (p. 62), ao discorrer sobre a Titanomaquia na p. 78, eles claramente consideram "caos" como um estado de confusão: "[...] todas as regiões diversas do cosmos, todos os elementos encontram-se de novo misturados numa confusão semelhante ao caos primordial. [...]". Veja-se também a p. 123: “[...] em Hesíodo, a narrativa teogônica desenvolve-se segundo um eixo linear, da desordem à ordem [...]". Em suma, sua noção de caos primordial hesiódico compreende um abismo sem fundo (p. 62), um estado de confusão com todos os elementos do cosmo misturados (p. 78) e desordem (p. 122-123). Vejam-se as p. 109112 para uma análise do papel de Tífon como um agente do caos e da desordem.

6 Para um comentário do proêmio enquanto um hino às Musas, elas próprias sujeito e objeto de seu canto, veja-se Pucci (2007). As edições e comentários consultados para este artigo são aqueles de West (1966), Most (2006), Arrighetti (1998) e Ricciardelli (2018).

7 Seu nascimento é narrado em 53-63 e mencionado novamente em 915-17.

Heródoto, Unifesp, Guarulhos, v.5, n.2 - 2020.2. p. 48-70.

DOI: $10.34024 /$ herodoto.2020.v5.12833 
verdades quando querem (27-28). ${ }^{8}$ Independente de o conteúdo de seu canto ser verdadeiro ou falso, seu conhecimento é totalizante, abrangendo o passado, o presente e o futuro, pois sabem "o que é, o que será e o que foi antes" (38). Como colocado por Bussanich (1983: 212), as Musas "são as vozes da memória cósmica". ${ }^{9}$ Além da autoridade desse conhecimento divino, sua canção assume importância também por seu poder glorificador, pois cantar sobre os deuses é glorificá-los (como se pode observar em 67 e 105).

Ao invocar tais deusas no início do proêmio, e depois ao reiterar a invocação ao seu final, o poeta consequentemente evoca delas o conhecimento, a partir do qual ele pode começar a cantar uma teogonia, isto é, uma canção acerca do nascimento dos deuses, e uma cosmogonia, ou seja, como o cosmo veio a se constituir, pois os deuses são elementos que compõem o cosmo. ${ }^{10}$

Próximo à metade do proêmio (43-46), nota-se uma preocupação evidente com o início do cosmo: "[...] Elas [as Musas], imorredoura voz emitindo /

\begin{abstract}
${ }^{8}$ A tradução utilizada neste artigo é a de Werner (2013), embora se tenha consultado com frequência a tradução de Torrano (1995). O debate suscitado pela declaração das Musas nos versos 27-28 é extenso. Vejam-se, por exemplo, Clay (2003: 58 e s.) e, em português, Brandão (2005: 75 e s.). De um ponto de vista externo ao poema, ao se declarar como porta-voz das Musas, o poeta também se declara como dependente delas quanto à sua narrativa. Como observa Clay (2003: 63-64), Hesíodo não pode garantir a veracidade absoluta de seu canto, pois o que ele narra na Teogonia está além do que é humano e, portanto, é inverificável. Ela aponta que, com a fala das Musas nos versos 27-28, revelase o hiato intransponível entre o conhecimento divino, disponível apenas aos deuses, que podem distinguir o verdadeiro daquilo que é falso mascarado de verdadeiro, e o conhecimento humano, que não consegue fazê-lo.

9 Enquanto "vozes de uma memória cósmica" ("voices of cosmic memory") que fornecem as canções ao poeta na tradição oral arcaica, elas podem também ser consideradas vozes que cantam uma "história do cosmo", já que essa tradição narra uma história desde a origem do cosmo, com a Teogonia de Hesíodo, até o momento presente do poeta, com Trabalhos e dias também de Hesíodo, abrangendo os hinos e os épicos homéricos. O conceito de "história do cosmo" não implica um discurso sobre fatos ou verdade histórica, mas o que a tradição considerou uma narrativa legítima sobre o passado. Para o uso do conceito de "história do cosmo" desenvolvido para os poemas em verso hexâmetro pertencentes à tradição oral arcaica na qual se inserem Homero e Hesíodo, veja-se Graziosi e Haubold (2005).

10 Composto por theós ("deus", "divindade") e gónos ("raça", "descendência", "procriação"), o título Teogonia não é atestado para o poema de Hesíodo antes do filósofo estoico Crisipo, que viveu no século III a.C., tendo sido possivelmente estabelecido pelos gramáticos alexandrinos. Entretanto, Heródoto, no século $\mathrm{V}$ a.C., utiliza o termo ao atribuir a Homero e Hesíodo a criação dos deuses para os helenos (2.53). Observe-se também o uso do termo por Heródoto (1.132) ao dizer que o Mágos persa canta uma teogonia.
\end{abstract}

Heródoto, Unifesp, Guarulhos, v.5, n.2 - 2020.2. p. 48-70.

DOI: $10.34024 /$ herodoto.2020.v5.12833 
dos deuses a veneranda raça primo glorificam no canto / dês o início, esses que Terra e extenso Céu pariram, / e estes que deles nasceram, os deuses oferentes de bens" (grifo meu). Tal preocupação é ainda mais evidente ao fim do proêmio, quando o poeta reitera sua invocação às Musas e lhes pede repetidamente que lhe narrem como no início (tà prốta, 108 e 113, ex arkhếs, 115) os deuses nasceram e qual deles foi o primeiro (prôton). ${ }^{11}$ Conforme já notado por Clay (2003: 72):

[...] Na verdade, o que é surpreendente é a repetida insistência de Hesíodo (tà prốta, 108, 113, prốton, 115; ex arkhếs, 115) no início correto; ele demanda das Musas que elas comecem no início absoluto e procedam de modo estritamente cronológico. (Minhas transliterações.)

As Musas, então, atendem ao pedido do pastor-poeta (22-23 e 26), dando início a uma genealogia do cosmo com aquele que surge em "primeiríssimo" (prốtista) lugar (116-125):12

Bem no início [ếtoi men prốtista], Abismo [Kháos] nasceu; depois [autár épeita],

Terra largo-peito, de todos assento sempre estável,

dos imortais que possuem o pico do Olimpo nevado,

o Tártaro brumoso no recesso da terra largas-rotas

e Eros, que é o mais belo entre os deuses imortais,

o solta-membros, e de todos os deuses e todos os homens

subjuga, no peito, espírito e decisão refletida.

De $\underline{\text { Abismo }[K h a ́ o s] ~ n a s c e r a m ~ E s c u r i d a ̃ o ~ e ~ a ~ n e g r a ~ N o i t e ; ~}$

de Noite, então, Éter e Dia nasceram,

que gerou, grávida, após com Escuridão unir-se em amor. 125

O verso 116 começa com étoi men, uma combinação de partículas que expressa uma forte asseveração (Denniston, 1954: 389), enfatizando o início

\footnotetext{
11 Teogonia 104-115: "Felicidades, filhas de Zeus, e dai canto desejável; / glorificai a sacra raça dos imortais sempre vivos, (105) / os que de Terra nasceram, do estrelado Céu / e da escura Noite, e esses que criaram o salso Mar. / Dizei como no início (tà prốta) os deuses e Terra nasceram, / os Rios e o Mar sem fim, furioso nas ondas, / os Astros fulgentes e o largo Céu acima, (110) / e esses que deles nasceram, os deuses oferentes de bens: / como a abastança dividiram, as honrarias repartiram, / e também como no início (tà prốta) ocuparam o Olimpo muita-dobra. / Disso me narrem, Musas que têm a morada olímpica, / do princípio (ex arkhếs), e dizei qual deles primeiro nasceu (prốton). (115)" (grifos meus).

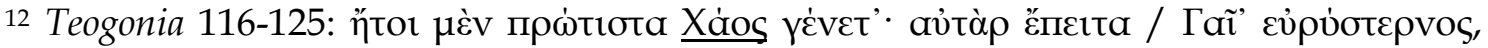

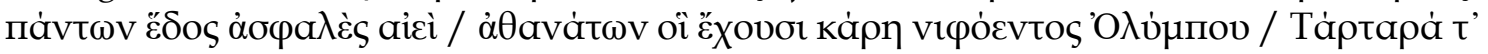

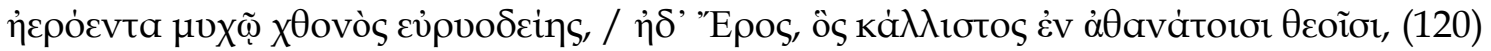

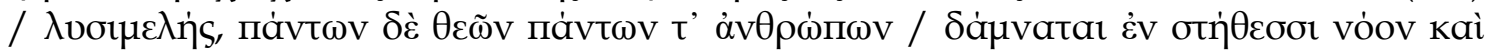

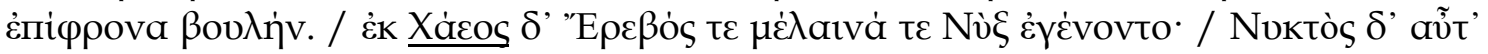

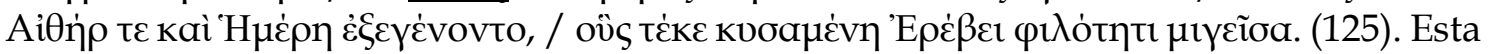
e todas as outras citações em grego da Teogonia são da edição de Most (2006).
}

Heródoto, Unifesp, Guarulhos, v.5, n.2 - 2020.2. p. 48-70.

DOI: $10.34024 /$ herodoto.2020.v5.12833 
da narrativa teogônica e cosmogônica com Kháos como o aquele que surge em primeiro lugar, e o uso do superlativo prốtista ("em primeiríssimo lugar", 116) acentua sua posição dianteira na sequência dos deuses primordiais, surgindo antes mesmo de Terra (Gaîa), que vem em seguida (116-118). Como as outras divindades primordiais, Kháos não nasce a partir de algum progenitor, mas simplesmente surge. É de ambos, Kháos e Terra, que o cosmo hesiódico descende (com exceção de Tártaro e Eros), mas não como um casal primordial, e parece importante à história teogônica e cosmogônica sendo narrada que o cosmo não venha da união deles, resultando em duas linhagens separadas. Isso implica que Terra não deve ter nascido de Kháos, e o texto é claro em relação a uma sequência expressa por autár épeita ("mas em seguida"). Diferente de "Terra largo-peito", Kháos não recebe qualquer qualificação ou explanação na passagem além da que informa sobre sua posição primeira. Ainda diferente de "terra", kháos é um termo cujo sentido não é evidente, encontrado apenas em quatro menções no poema (116, 123, 700 e 814). ${ }^{13}$ Ademais, o uso posterior da palavra kháos parece derivar seu sentido das diferentes interpretações do Kháos hesiódico.

Traduzindo-o por "Chasm" ("Abismo"), Most (2006: 13, n. 7) aponta o caráter enganador ao se verter Kháos por "Chaos" ("Caos"), um cognato que leva o leitor a pensar numa "confusão de matéria desordenada". Conforme mencionado anteriormente, essa não é a concepção de Kháos encontrada na Teogonia de Hesíodo. É possível que ela tenha se tornado corrente depois do poeta romano Ovídio, cujo poema Metamorfoses apresenta Chaos - a grafia latinizada de Kháos - como uma massa confusa e sem forma de elementos discordantes que era o estado do cosmo antes do aparecimento do oceano, da terra e do céu. ${ }^{14}$ Tal sentido de desordem e de matéria sem forma é também encontrado em Amores (32) de Luciano de Samósata (século II d.C.). ${ }^{15}$ Mais tarde, no século V d.C., Agostinho de Hipona atribui aos gregos a concepção de chaos encontrada no poema de Ovídio: "primeiro, portanto, a matéria era confusa e sem forma, de onde

\footnotetext{
${ }^{13}$ Quando não iniciadas com maiúscula, as palavras "kháos" e "terra" são tomadas como substantivos comuns.

14 Ovídio, Metamorfoses 5-9: Ante mare et terras et quod tegit omnia caelum / unus erat toto naturae vultus in orbe, / quem dixere Chaos; rudis indigestaque moles / nec quicquam nisi pondus iners congestaque eodem / non bene iunctarum discordia semina rerum. "Antes do mar e da terra, e do céu que tudo cobre, / era uniforme em todo o orbe o aspecto da natureza, / à qual chamaram Caos: massa confusa e informe, / apenas peso inerte, amálgama discordante / de elementos mal unidos." (Tradução de Dias, 2017).

15 Apud Kirk (1957: 27), que atribui a origem dessa noção aos filósofos estoicos.
}

Heródoto, Unifesp, Guarulhos, v.5, n.2 - 2020.2. p. 48-70.

DOI: $10.34024 /$ herodoto.2020.v5.12833 
vieram todas as coisas que são distintas e formadas, isso é o que acredito ter sido nomeado chaos pelos gregos". ${ }^{16}$

Embora a tradução como Abismo evite a sobreposição entre o Kháos hesiódico e o caos como uma "confusão de matéria desordenada", ela implica numa leitura em que a palavra kháos seja identificada com khásma ("abertura", "abismo"). Tal identificação é baseada fundamentalmente em dois argumentos. Primeiro, a palavra khásma é usada na Teogonia (740) ao início da descrição do Tártaro na expressão khásma méga ("grande abismo"), designando uma fenda cujo chão não é atingível mesmo depois de uma queda de um ano de duração. ${ }^{17}$ Ao final da descrição do Tártaro, os versos 736-739, que antecedem a menção ao khásma méga em 740, são repetidos em 807-810, mas dessa vez Kháos zopherô̂o ("abismo penumbroso") é mencionado no lugar de khásma méga. Essa identificação é difícil de refutar, pois khásma méga e Kháos zopherô̂o parecem ocupar o mesmo lugar cosmográfico. Solmsen (1950: 238) assevera que "khásma é o mesmo que kháos". West (1966: 192) considera que Kháos é mais bem traduzido como "Chasm" ("Abismo") e é também a favor de sua identificação com khásma, como Podbielski (1986). Abismo é, portanto, a interpretação atualmente predominante para o Kháos hesiódico, como pode ser observado na edição de West, nas traduções de Most e Werner, e

16 Tradução própria. De Genesi contra Manich. 1.5.9: primo ergo materia facta est confusa et informis unde omnia fierent quae distincta et formata sunt quod credo a Graecis chaos appellari (apud Solmsen, 1950: 235-236, n. 4).

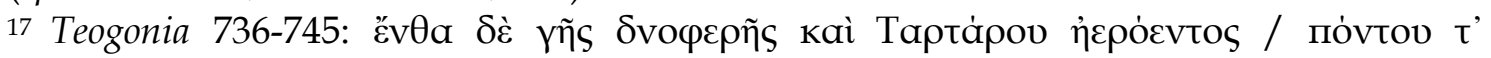

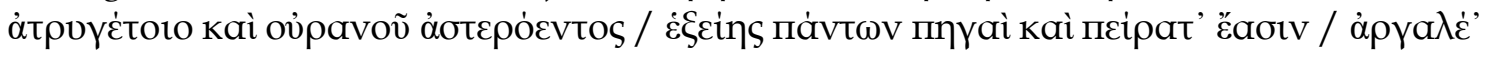
عủ

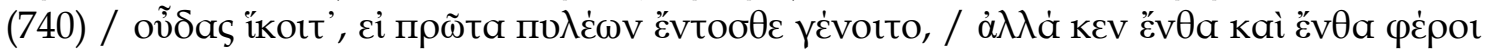

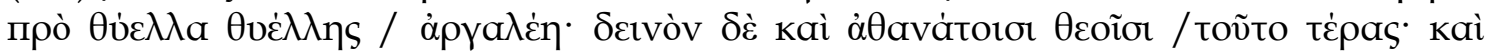

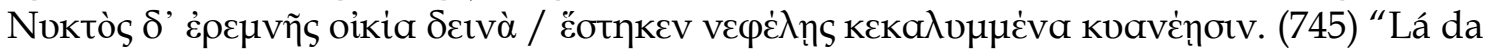
terra escura, do Tártaro brumoso, / do mar ruidoso e do céu estrelado / as raízes e limites, de tudo, em ordem estão, / aflitivos, bolorentos, aos quais até os deuses odeiam: / grande fenda, e nem no ciclo de um ano inteiro (740) / o chão alguém atingiria, os portões uma vez cruzados, / mas p'ra lá e p'ra cá o levaria rajada após rajada, / aflitiva. Assombroso é também para deuses imortais / esse prodígio; também a morada assombrosa de Noite / encontra-se escondida em nuvem cobalto. (745)." Compare-se a descrição do Tártaro nos versos 721-725: "Tal a distância da terra até o Tártaro brumoso. / Pois por nove noites e dias bigorna de bronze, / caindo do céu, no décimo a terra alcançaria / (por sua vez, igual da terra até o Tártaro brumoso). / De novo, por nove noites e dias bigorna de bronze, / da terra caindo, no décimo o Tártaro alcançaria. (725)".

Heródoto, Unifesp, Guarulhos, v.5, n.2 - 2020.2. p. 48-70.

DOI: $10.34024 /$ herodoto.2020.v5.12833 
em várias publicações que lidam com a Teogonia, como Détienne e Vernant (2008: 62) e Muellner (1996: 55). ${ }^{18}$

O segundo argumento, que reforça o primeiro, é a possível ligação etimológica entre kháos e khásma. Embora Chantraine (1980: 1256) não mencione qualquer relação entre eles, Beekes (2010: 1614) sugere uma antiga conexão entre o grupo kháos/khaûnos, com khaûnos significando "poroso", "esponjoso", e kháskō/khásma/khaneîn, estes todos relacionados à ação de "abrir", "escancarar". Em sua breve mas cuidadosa reavaliação da evidência etimológica, Mondi (1989: 7) conclui que ambos os grupos são derivados de raízes diferentes, não tendo qualquer ligação direta entre eles. Não obstante, indiferente de uma relação etimológica entre kháos e khásma, nada impede que Hesíodo tenha estabelecido uma conexão entre eles, considerando que esse poeta constrói outras relações etimológicas em seu poema, por vezes denominadas "falsas etimologias", como aquela para o nome Afrodite (194-200), assim nomeada por ter nascido da "espuma" (aphrós) formada em torno do pênis de Céu (Ouranós) que foi lançado no mar por Crono (188 e s.). De todo modo, uma identificação de kháos com khásma não necessariamente precisa se basear numa relação etimológica, já que certo intercâmbio entre eles pode ser observado no próprio poema. Além disso, a definição de uma palavra é tão ou mais determinada pelo uso do que por sua origem etimológica. O problema com Kháos é que o poema não fornece tantas instâncias de uso ou tantos contextos suficientes para uma identificação mais precisa de seu sentido. As observações etimológicas ganham, portanto, muita importância de modo que se tornam argumentos decisivos. Isso é compreensível, já que são um dos poucos instrumentos disponíveis para se tentar entender o sentido de Kháos na Teogonia, todavia, seu uso como argumento final e decisório é questionável.

Depois das primeiras duas ocorrências de Kháos entre os versos 116-125, a terceira se encontra ao final do episódio da Titanomaquia (617-721), no momento que Zeus golpeia os Titãs, lançando raios que abalam os fundamentos do cosmo. Kháos é mencionado como um dos lugares atingidos pelos efeitos de tais raios (687-705): 19

\footnotetext{
18 Solmsen (1950: 235, n. 1) aponta que a associação de Kháos com abismo pode ser traçada desde Jacob Grimm, que o compara ao ginnungagap nórdico. Para as razões pelas quais tal comparação ao ginnungagap é equivocada, veja-se Mondi (1989: 8, n. 22).

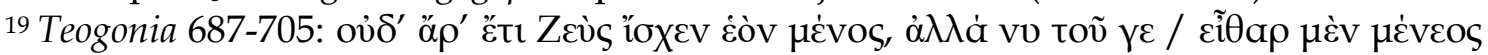

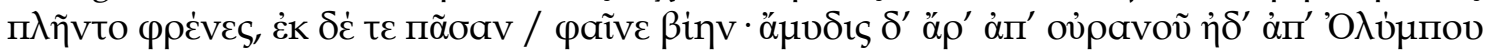

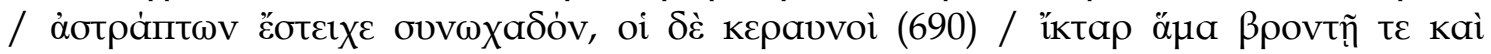

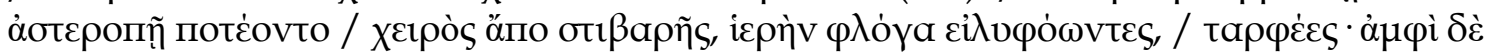

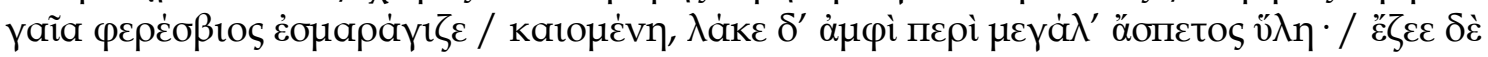

Heródoto, Unifesp, Guarulhos, v.5, n.2 - 2020.2. p. 48-70.

DOI: $10.34024 /$ herodoto.2020.v5.12833 
E Zeus não mais conteve seu ímpeto, mas dele agora

de pronto o peito encheu-se de ímpeto, e toda

a força mostrou. Ao mesmo tempo, do céu e do Olimpo

relampejando, progrediu sem parar, e os raios

em profusão, com trovão e relâmpago, voavam

de sua mão robusta, revolvendo a sagrada chama,

em massa. Em volta, ribombava a terra traz-víveres,

queimando, e, no entorno, alto chiava o mato incontável.

Todo o solo fervia, as correntes de Oceano

e o mar ruidoso. A eles rodeava o quente bafo,

aos terrestres Titãs, e chama alcançou a bruma divina,

indizível, e aos olhos deles, embora altivos, cegou

a luz cintilante do raio e do relâmpago.

Prodigiosa queimada ocupou o abismo [Kháos]; parecia, em face 700

olhando-se com olhos e com ouvidos ouvindo-se o rumor,

assim como quando Terra e o largo Céu acima

se reuniram; tal baque, enorme, de baixo veio,

ela pressionada e ele, do alto, pressionando -

tamanho baque veio da briga de deuses se atracando.

705

O embate de proporções cósmicas afeta as fundações mesmas do cosmo: Terra queima, as correntes do rio Oceano e o mar fervem, uma chama atinge a "bruma divina" (ou "Aithếr divino") e Kháos é tomado por uma queimada (kaûma) prodigiosa. ${ }^{20}$ Dessa passagem é possível inferir, portanto, que Kháos, além de ser uma entidade primordial, é também um lugar, como os primordiais Terra e Tártaro, e a mesma lógica parece se aplicar ao Aithếr, neto de Kháos (123-125, traduzido como Éter no verso 124). ${ }^{21}$ Portanto, Terra, Tártaro e Kháos pertencem a uma teogonia, a uma

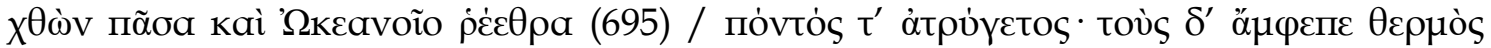

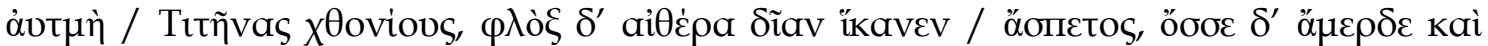

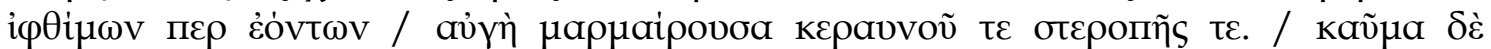

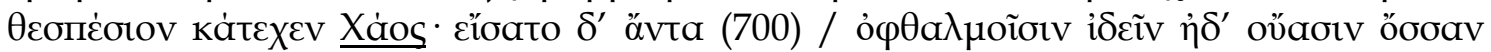

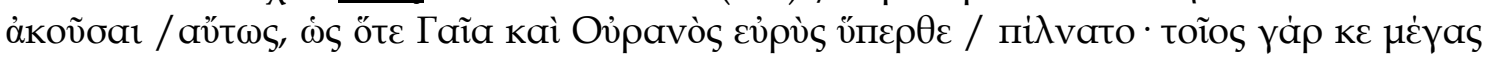

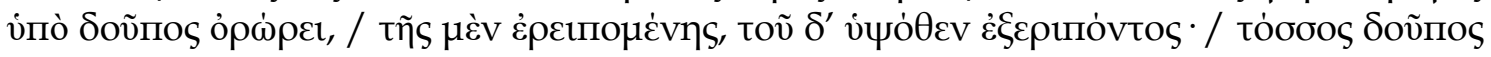

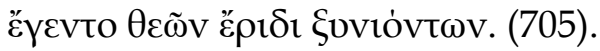

${ }^{20}$ Note-se que nessa passagem Werner não utiliza Kháos com letra maiúscula nem "bruma", sua tradução para Aithếr em 697. Ao não utilizar a letra maiúscula, o editor ou tradutor indica que, naquele contexto, o termo não está sendo usado como um nome próprio e, portanto, seu referente não está sendo entendido como uma divindade. É difícil saber, contudo, se poeta e público fariam tal distinção, especialmente no caso de aithếr, que está sendo qualificado como "divino" nesse contexto. Muito possivelmente não há tal distinção para a tradição oral da qual a Teogonia deriva.

${ }^{21}$ Considero Tártaro uma das divindades primordiais, junto com Kháos, Terra e Eros. Embora os versos 118-119 tenham sido ignorados por Platão (Banquete 178b) e Aristóteles (Metafísica 984a27), West (1966: 193-195) os mantém como uma adição posterior do poeta, Most (2006) não os exclui, Arrighetti (1998) argumenta que a não menção deles por Platão e Aristóteles é insuficiente para considerá-los espúrios e Ricciardelli (2018) não

Heródoto, Unifesp, Guarulhos, v.5, n.2 - 2020.2. p. 48-70.

DOI: $10.34024 /$ herodoto.2020.v5.12833 
cosmogonia, bem como a uma cosmografia, na qual essas divindades que são lugares ou "divindades-lugar" são circunscritas num mapa do cosmo e, ao mesmo tempo, o circunscrevem. Desse modo, tem-se a primeira pista do que Kháos representa na cosmogonia hesiódica fornecida pelo próprio poema: ele é fundamentalmente um lugar na cosmografia teogônica.

Com base nessa passagem, Kháos tem sido interpretado como a região entre terra e céu, pois a batalha tem lugar acima do chão (Kirk, 1957: 26-32), entretanto, ela pode simplesmente indicar que a batalha de proporções cósmicas afeta o cosmo em sua totalidade num eixo vertical, do lugar mais alto ao mais baixo, com a chama provocada pelos raios de Zeus alcançando o Aithếr acima, e a queimada ou seu calor atingindo o Kháos abaixo. O argumento contra a interpretação de Kháos como a região entre terra e céu é fornecido pelo próprio poema, ao final da descrição do Tártaro, quando Kháos é mencionado pela última vez (807-814):22

Lá da terra escura, do Tártaro brumoso, do mar ruidoso e do céu estrelado

parece se opor à sua manutenção. Mesmo que eles sejam mantidos como autênticos, há ainda a possibilidade de que, como neutro plural (Tártara), Tártaro seja um acusativo objeto de ékhousi ("têm", "ocupam", "habitam"), presente no verso 118, designando a extremidade inferior em contraposição à extremidade superior, o Olimpo, dentre os locais ocupados pelos imortais (Most, 2004: 178-180). Nessa leitura, Terra é assento firme tanto dos imortais que ocupam (ékhousi) o Olimpo como dos que ocupam o Tártaro. Tal interpretação tem força principalmente pela ocorrência do neutro plural Tártara em lugar do masculino singular, que também ocorre em 841 na expressão Tártara gaíes (traduzida como "nos Tártaros da terra"). Em outras passagens (682, 721, 725, 736 = 807, 822 e 868), Tártaro ocorre no masculino singular. Não há, contudo, qualquer impedimento relativo à gramática para que, como nominativo neutro plural (Tártara), Tártaro esteja dentre as divindades primordiais. A principal razão, a meu ver, para Tártaro estar dentre elas é que, tendo essa divindade-lugar papel de destaque na cosmografia da Teogonia e não havendo menção à sua origem nos quase cem versos que se ocupam de sua descrição, o verso 119 é a única possibilidade de encontrá-la no poema. Considerando a importância dada à origem das divindades num poema cujo tema principal se centra nessa origem, é difícil aceitar que o poeta deixaria de mencionar seu surgimento. Ademais, Tártaro será o pai de Tífon/Tifeu no poema, fruto de sua união com Gaia, e o rebento será vencido por Zeus como seu derradeiro inimigo e opositor de sua ordem. Contra, veja-se, por exemplo, Bussanich (1983: 212, n. 2), para quem não se deve considerar Tártaro uma das divindades primordiais independente de os versos 118-119 serem ou não uma interpolação. Para uma síntese das argumentações em torno de Tártaro ser ou não uma divindade primordial, veja-se Wacziarg (2001: 144-146).

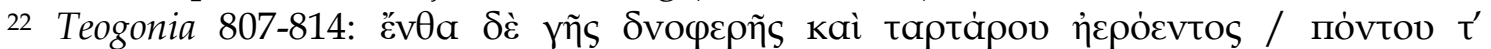

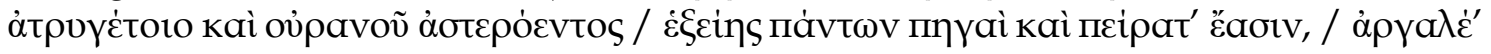

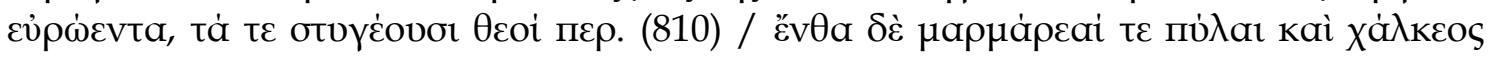

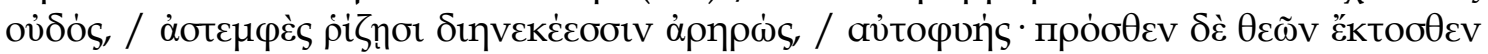

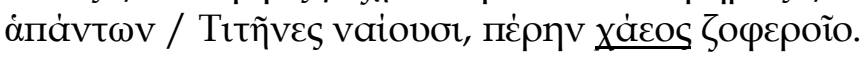

Heródoto, Unifesp, Guarulhos, v.5, n.2 - 2020.2. p. 48-70.

DOI: $10.34024 /$ herodoto.2020.v5.12833 
as raízes e limites, de tudo, em ordem estão,

aflitivas, bolorentas, coisas que até os deuses odeiam.

Lá ficam os portões luzidios e o umbral de bronze,

ajustados, imóveis, com raízes contínuas,

naturais; na frente, longe de todos os deuses,

os Titãs habitam, para lá do abismo penumbroso.

Encarcerados e à parte dos demais deuses, os Titãs habitam "para lá do Kháos zopherós" ("escuro", "sombrio"). Nessa passagem, Kháos é colocado como um limite para o Tártaro, onde os Titãs passaram a habitar após serem aprisionados. Aqui se tem a segunda pista em relação ao Kháos, sua escuridão, expressa pelo adjetivo zopherós, e também a terceira: ele não é, ou não é mais, um espaço ilimitado, pois se localiza, na perspectiva do poeta ou das Musas, antes dos portões do Tártaro.

\section{O Kháos e a escuridão}

Conforme mencionado anteriormente, os versos 807-810, próximos ao fim da descrição do Tártaro, são encontrados em 736-739, catorze versos depois do início da descrição. É nessa passagem que o poeta usa Kháos zopherós em lugar de khásma méga, razão principal para serem considerados sinônimos. Se khásma e Kháos parecem ocupar o mesmo lugar cosmográfico no poema e são termos semelhantes ao menos sonoramente, embora sua relação etimológica não seja conclusiva, a identificação de um com o outro não é despropositada. Ainda assim, se khásma e Kháos designam o mesmo lugar cosmográfico, por que Hesíodo denomina sua divindade-lugar primordial Kháos e não Khásma, já que esta última é uma palavra de significado menos abstruso? ${ }^{23}$ Tanto Tártaro como Terra, divindades-lugar primordiais cujo surgimento segue o de Kháos têm nomes que não são de difícil compreensão; mesmo Tártaro não sendo tão óbvio quanto Terra, o poema dedica quase cem versos à sua descrição. Por que as Musas dariam a Hesíodo como origem do cosmo uma entidade divina cujo sentido não é suficientemente claro? Ou por que o poeta daria a seu público uma entidade primordial cujo sentido não é prontamente apreendido?

\footnotetext{
${ }^{23}$ Mondi (1989: 9) sugere que kháos e khásma diferem quanto ao nível de generalização, pois " [...] khásma pode ser usado para qualquer coisa com uma configuração física de um fosso ou cavidade, enquanto kháos é primeiramente um termo cósmico; em outras palavras, há muitos khásmata, mas apenas um kháos" (minhas transliterações). Mesmo que essa explicação possa ser convincente, ela não elimina as questões colocadas em seguida.
}

Heródoto, Unifesp, Guarulhos, v.5, n.2 - 2020.2. p. 48-70.

DOI: $10.34024 /$ herodoto.2020.v5.12833 
Como observado por Paula Philippson (apud Podbielski 1986: 257), Hesíodo define a natureza dos deuses pelo nome, pelo epíteto e pela progênie. No caso de Kháos, seu nome não é claro, sua qualificação ocorre unicamente pelo adjetivo zopherós (814), restando apenas à sua progênie o potencial para fornecer uma compreensão mais precisa dessa entidade primordial.

Por ora, contudo, o foco recairá no único adjetivo atribuído a Kháos na Teogonia: zopherós (814), "escuro", que é um hápax legómenon, ou seja, esta é sua única ocorrência em toda a poesia oral tradicional em hexâmetro. Como Kháos, ele não encontra ocorrência nos poemas de Homero - não há, inclusive, qualquer indício de que Kháos faça parte da concepção teogônico-cosmogônica presente na Ilíada e na Odisseia. ${ }^{4}$ Entretanto, Homero utiliza o substantivo zóphos ("escuridão", "treva"), que também ocorre na Teogonia na fórmula zóphos éeróeis $(653,658$ e 729). A primeira ocorrência dessa fórmula no poema de Hesíodo está na fala de Zeus aos Centímanos, ao pedir que se aliem a ele e se insurjam contra os Titãs em troca de terem sido retirados de "sob a treva brumosa". Os Centímanos eram mantidos aprisionados por seu pai, Céu, sob o chão, nos confins da Terra (617-623). A fórmula zóphos éeróeis encontra-se repetida por Coto, um dos Centímanos, em resposta a Zeus (658). E, por fim, o narrador a menciona na descrição do Tártaro, relacionando-a ao local em que os Titãs foram aprisionados. Na Teogonia, portanto, o zóphos eeeróeis ou a "treva brumosa" está associada ao ambiente subterrâneo, aos confins da Terra e ao Tártaro.

Na Ilíada, a fórmula ocorre predominantemente em relação ao Hades (15.191, 21.56 e 23.51). Como um poema que narra outro momento na história do cosmo no qual Zeus já ascendera ao poder supremo e a divisão do cosmo entre Zeus, Posêidon e Hades já ocorrera, a "treva brumosa" (zóphos éeróeis) passa a ser relacionada ao Hades, que ocupa nessa nova ordem o lugar físico e conceitual que Tártaro assumia para a ordem divina anterior. ${ }^{25}$ Há, contudo, uma ocorrência (12.240) em que a expressão "rumo à treva brumosa" está em contraposição ao lado direito, "rumo à aurora e

${ }^{24} \mathrm{Na}$ Ilíada o rio Oceano e Tethys são o casal primordial segundo a fala da deusa Hera em 14.187-210 e 14.302-311 e a resposta de Sono a Hera em 14.243-246.

25 Observe-se a passagem da Ilíada em torno de 15.191 em que Posêidon menciona à deusa Íris a divisão tripartite entre ele próprio, Zeus e Hades, na qual este último "obteve a terra brumosa". Para outras ocorrências da fórmula zóphos ēeróeis, vejam-se também: 21.56 em que Aquiles, ao ver Licáon, filho de Príamo, que havia sido vendido por Aquiles em Lemnos, fala acerca da possibilidade de os mortos se "erguerem da treva brumosa"; e 23.51, em que Aquiles se refere ao corpo de Pátroclo como "o morto que desce às trevas brumosas". A tradução da Ilíada utilizada é a de Werner (2018).

Heródoto, Unifesp, Guarulhos, v.5, n.2 - 2020.2. p. 48-70.

DOI: $10.34024 /$ herodoto.2020.v5.12833 
ao sol", quando Heitor se dirige a Polidamas se referindo ao voo dos pássaros como augúrio. É certo que, como na Teogonia, na Ilíada a "treva brumosa" é associada ao mundo subterrâneo, mas ela também é associada ao oeste e ao lado esquerdo, uma relação que encontra mais frequência na Odisseia. Nesse poema, como na Ilíada, a fórmula ocorre em referência ao Hades (11.57 e 11.155) e também numa construção que contrasta a "direção da aurora e do sol" e aquela "rumo à treva brumosa" (13.241). ${ }^{26} \mathrm{O}$ uso de zóphos fora da fórmula, algo que não ocorre na Ilíada, não deixa dúvidas de que a escuridão ou as trevas se localizam também a oeste, a região em que o sol se põe $(O d .3 .335,9.26$ e 10.190), e suas outras ocorrências fora da fórmula associam, ademais, o zóphos ao Érebo (Od. 12.81 e 20.356), que, por sua vez, associa-se ao Hades na fala de Teoclímeno aos pretendentes ao dizer que os espectros anseiam ir "ao Érebo rumo às trevas". Há, portanto, na localização da "treva brumosa" em Homero uma verticalidade, mas também uma horizontalidade, esta indicada pela região onde o sol se põe. Com a entrada do Érebo e do Hades localizada no ocidente, há uma associação clara entre o que está no extremo oeste e o que está no subterrâneo, tendo a escuridão como ponto em comum.

Assim, Tártaro, o ambiente subterrâneo e os confins da Terra estão ligados na Teogonia, como trevas, Hades e o oeste ou o ocaso o estão na Ilíada e na Odisseia. Neste último poema, há também a associação direta de Érebo ao oeste (12.81) e ao Hades (20.356). Na Teogonia, Érebo é o primogênito de Kháos (123).

Considerada por West a carne e o sangue da Teogonia, a genealogia é a forma essencial sob a qual o poema hesiódico explica o cosmo. As genealogias estabelecem relações de origem que são explicativas de como o cosmo se constitui, portanto, entender quem são os filhos ajuda a entender quem são os pais, seja por razão de semelhança ou contraste.

\footnotetext{
${ }^{26} \mathrm{Na}$ Odisseia, a fórmula ocorre para se referir ao Hades tanto em 11.57, na fala de Odisseu a Elpenor, como em 11.155, na fala de Anticleia a Odisseu, quando ele desce ao mundo subterrâneo; em 13.241 ela ocorre na fala de Atena a Odisseu em semelhante construção que contrasta a "direção da aurora e do sol" e a "rumo à treva brumosa". Diferente da Ilíada, na Odisseia o termo zóphos ocorre sozinho, fora da fórmula: em 3.335 na fala de Atena a Nestor ("A luz já desceu rumo às trevas"), em referência ao pôr do sol; em 9.26 na fala de Odisseu ao rei Alcínoo ao lhe contar que vem de Ítaca, a "última [ilha] rumo às trevas"; em 10.190 na fala de Odisseu expressando que não sabe onde está ("Amigos, não sabemos onde é a treva, onde a aurora"); em 12.81 na fala de Circe a Odisseu ("No meio do penedo há uma gruta penumbrosa, / voltada para o oeste [zóphos], rumo ao Érebo [...]"); em 20.356 na fala de Teoclímeno aos pretendentes ("cheio de espectros está o vestíbulo, cheio, o pátio, / ansiando ir ao Érebo rumo às trevas [...]."). A tradução da Odisseia utilizada é a de Werner (2018).
}

Heródoto, Unifesp, Guarulhos, v.5, n.2 - 2020.2. p. 48-70.

DOI: $10.34024 /$ herodoto.2020.v5.12833 
Desse modo, a progênie de Kháos é fundamental para sua compreensão no poema. Imediatamente após o surgimento das divindades primordiais Kháos, Terra, Tártaro e Eros, são os descendentes de Kháos os primeiros a serem gerados de alguém (v. 124-126):27

De Abismo [Kháos] nasceram Escuridão e a negra Noite;

de Noite, então, Éter e Dia nasceram,

que gerou, grávida, após com Escuridão unir-se em amor.

O par de irmãos Érebo (traduzido como "Escuridão" por Werner) e Noite são os primogênitos de Kháos, inaugurando a linhagem dessa entidade cujo nome pertence ao gênero gramatical neutro. Talvez seja significativo que $o$ poeta mencione os primeiros descendentes de Kháos antes dos que descendem de Terra, pois não haveria prejuízo em mencioná-los imediatamente antes da linhagem da Noite, após o episódio da castração de Céu, a partir do verso 211. Por alguma razão, o nascimento de Érebo, Noite, Éter e Dia é colocado no poema antes de Terra iniciar sua própria linhagem dando origem ao Céu.

Tanto Érebo como Noite, os dois filhos gerados de Kháos sozinho, apresentam o aspecto da escuridão: aquele como a escuridão subterrânea e Noite como a escuridão supraterrânea, cuja morada está associada ao espaço subterrâneo em 744-745 (veja o texto na nota 16). Nesse processo de partenogênese, é possível supor um desdobramento de Kháos, semelhante àquele de Terra ao gerar Céu "igual a si própria" (126-127). O processo teogônico e cosmogônico na Teogonia de Hesíodo é caracterizado pelo desdobramento nas entidades geradas de aspectos conceituais presentes ou ao menos associados à entidade originária.

Embora tenham sido gerados numa espécie de reprodução assexuada, os irmãos filhos de Kháos inauguram no poema a reprodução sexuada, formando um casal: Noite, a parte feminina, gera Éter e Dia, após "se unir em amor" (philótēti migeîsa) com seu irmão Érebo e engravidar (kysaménē). Tal união só é possível pela existência de Eros como uma das divindades primordiais, a única dentre elas que não seria uma divindade-lugar, mas se configura como o princípio da união, que torna possível duas divindades se unirem e procriarem. ${ }^{28}$ Eros não pode ser uma divindade-

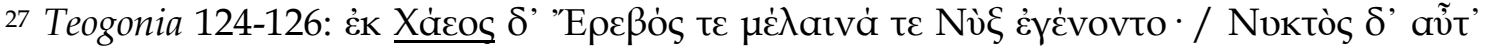
Aïn่

28 Talvez seja possível especular que Kháos e Terra não formem um casal primordial na concepção teogônica de Hesíodo porque surgem antes de Eros, ou o contrário: o surgimento de Eros lhes é posterior porque Kháos e Terra não devem constituir um casal primordial nessa concepção teogônica.
}

Heródoto, Unifesp, Guarulhos, v.5, n.2 - 2020.2. p. 48-70.

DOI: $10.34024 /$ herodoto.2020.v5.12833 
lugar porque, a partir de seu surgimento, ele deve estar em todos os lugares, presidindo uniões que gerarão as partes constituintes do cosmo. ${ }^{29}$ É também notável que a primeira união sexual do poema produza uma espécie de contraparte de seus pais.

Se Érebo e Noite trazem em si aspectos de seu progenitor Kháos, e se a característica que se pode presumir nos filhos é a escuridão, Kháos também deve contê-la em si, um traço que lhe é claramente atribuído no próprio poema pelo adjetivo zopherós em 814 .

O poema poderia seguir com os descendentes da Noite, mas após os três versos em que se vislumbra a linhagem de Kháos, o poema se volta à linhagem da Terra (126-153) e à narrativa do primeiro mito de sucessão, aquele entre Céu e seu filho Crono (v. 154-210), para retornar à progênie da Noite apenas em 211-232. Antes de seguir com a linhagem da Noite, este artigo também fará um breve desvio em seu percurso.

\section{O ar, o espaço, o ilimitado, o vazio}

No século V a.C., Baquílides (epinício 5.16-30) compara o espaço ilimitado através do qual a águia de Zeus pode lançar voo com a ilimitada fonte de criatividade poética da qual o poeta bebe. ${ }^{30} \mathrm{Na}$ designação de tal espaço, ele usa o termo kháos. O escólio ao verso 116 da Teogonia menciona a interpretação de Baquílides: "Baquílides nomeou kháos o ar, ao falar acerca da águia" (tradução própria). ${ }^{31}$ Apesar de Mondi (1989: 16-17) comentar sobre a possibilidade de Baquílides utilizar kháos como um espaço ilimitado enquanto metáfora para a ilimitada fonte da criatividade poética e não como espaço entre a Terra e o Céu, o poeta usou kháos para se referir ao espaço no qual voa a águia, seja ele entendido como ar, conforme sugerido pelo escoliasta da Teogonia, ou como um abismo, na tradução de

\footnotetext{
29 Torrano (1996, p. 43), no ensaio que acompanha sua tradução da Teogonia, explica o Kháos primordial partindo de uma relação com o verbo khaínō e sua variante kháskō, "abrir-se, entreabrir-se" e "abrir a boca, as fauces ou o bico", visto como "a força que preside à separação" em contraposição a Eros, "a força que preside a união amorosa". Kháos seria um "cissor", presidindo a reprodução assexuada por uma espécie de cissiparidade, modo sob o qual ele dá origem a seus filhos.

30 Baquílides, epinício 5.16-30: "[...] Rasgando / no alto o céu profundo com / fulvas asas céleres, / a águia - mensageira do amplireinante / Zeus altitrovejante - (20) / é resoluta, confiando em sua robusta / força, e com medo se ocultam / os pássaros clarissonantes; / não a limitam os cimos da grande terra, / nem as turbulentas ondas (25) / do mar infatigável. Meneia / no infindo abismo / as delicadas penas da plumagem / com rajadas do vento oeste / conspícua aos homens de se ver. (30)" (tradução de Ragusa, 2013: 219-220).

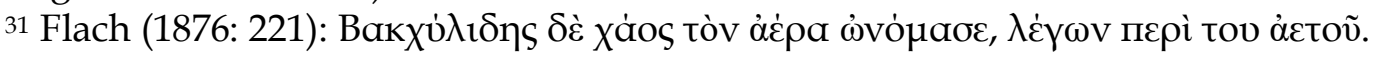

Heródoto, Unifesp, Guarulhos, v.5, n.2 - 2020.2. p. 48-70.

DOI: $10.34024 /$ herodoto.2020.v5.12833 
Ragusa, ou, ainda, como o vazio ("void"), na tradução para o inglês de Jebb (1905). Esse uso de kháos por Baquílides apresenta certa relevância por ter sido apontado por um escoliasta num comentário ao verso 116 da Teogonia.

Ainda no século V a.C., Aristófanes em As Nuvens faz Sócrates explicar a Estrepsíades que o panteão dos sofistas consiste na tríade Kháos, as Nuvens e a Língua (424) e no verso 627 Sócrates profere uma jura "pelo Sopro, Kháos e Ar". ${ }^{32}$ Mondi (1989: 20-21) aponta que Aristófanes pode estar simplesmente ironizando a vacuidade do discurso sofístico. Entretanto, a associação de kháos a algo relacionado ao ar na passagem é difícil de refutar, embora não deva ser $o$ ar exatamente.

Não obstante, em outra comédia de Aristófanes, As Aves (690-99), Kháos é a primeira divindade a surgir na construção da cosmogonia proferida pelo coro de aves, antes de Noite, Érebo e Tártaro, reunindo nessa cosmogonia entidades ligadas à escuridão. ${ }^{33}$ Assim, é possível encontrar no mesmo autor um uso flexível de Kháos quanto às associações possíveis de lhe serem atribuídas ao menos no século V a.C. É digno de menção que Aristófanes parece usar Kháos estritamente em cosmogonias que ele cria para seus personagens cômicos, e não como um substantivo comum, como o faz Baquílides.

Aristóteles (Física 208b29-209a2) cita o verso 116 da Teogonia (com uma pequena variação: pántōn no lugar de étoi) e oferece sua interpretação do Kháos hesiódico como um "espaço" (khốra) no qual as coisas existem. ${ }^{34}$ Kirk (1957: 26) descarta tal interpretação do Kháos hesiódico por ser muito

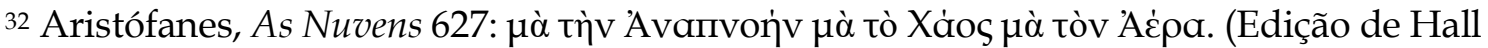
e Geldart, 1907.)

${ }_{33}$ Aristófanes, As Aves 693-699: "No início era o Caos e a Noite, o negro Érebo e o vasto Tártaro / nem a Terra, o Ar ou o Céu existiam. No seio infinito de Érebo, / a Noite de negras asas gera, primeiro, um ovo de vento, (695) / do qual, cumprido o ciclo das estações, nasceu Eros, o desejado, / a cujo dorso áureas asas dão brilho, semelhante aos vórtices do vento. / Ele ao alado Caos noturno tendo-se unido no Tártaro vasto, / chocou nossa raça e primeiro a trouxe à luz." (tradução de Duarte, 2000).

34 Aristóteles, Física 208b29-209a2: "Hesíodo parece dizer o certo ao colocar kháos primeiro. Ele diz 'de todos, em primeiríssimo lugar, surgiu kháos, e em seguida terra amplo-peito', porque é necessário haver primeiro um espaço [khốra] para os entes, e deve julgar, como muitos, que todas as coisas existem em algum lugar [tópos]. Sendo assim, notável é a função do lugar [tópos] e sua anterioridade em relação a tudo, pois sem ele nada das outras coisas existe, mas ele existe sem elas, sendo necessário ser o primeiro. Pois o lugar [tópos] não é destruído se as coisas nele forem aniquiladas. (Tradução própria a partir da edição de Ross, 1936.) Observe-se que a tradução de Kháos como Abismo não faria muito sentido para o texto de Aristóteles. Mondi (1989: 1-2) sugere que talvez Aristóteles tenha considerado alguma relação etimológica entre kháos e khốra.
}

Heródoto, Unifesp, Guarulhos, v.5, n.2 - 2020.2. p. 48-70.

DOI: $10.34024 /$ herodoto.2020.v5.12833 
posterior a Hesíodo, embora ele a identifique em Pitágoras, Zenão de Eleia e no Timeu de Platão. Bussanich (1983: 218) parece seguir Aristóteles ao definir Kháos como "um princípio passivo no qual a manifestação cósmicodivina ocorre", mas na verdade o compara ao Receptáculo enquanto "espaço" (khốra) no Timeu (52B1) de Platão, no qual as coisas vêm a ser (50D1 e 52C4) e cujo caráter desprovido de substância seria um tanto similar ao de Kháos.

Mondi (1989: 23 e s.) explora a possível relação etimológica de kháos e o adjetivo khaûnos ("esponjoso", "poroso"), embora esse termo seja atestado apenas a partir do século $\mathrm{V}$ a.C., sendo um tanto posterior a Hesíodo. As passagens em vários autores nas quais tal termo aparece indicam seu uso para expressar uma falta de forma definida ou rígida, e os termos dele derivados também apontam certa ausência de materialidade. Partindo dessa relação, Mondi (1989: 25) estabelece a seguinte definição para kháos na Teogonia:

O que kháos representa para Hesíodo é algo intermediário entre a não existência e a existência: o estado ou condição da ausência de forma e diferenciação considerada ela própria uma entidade. E como forma e diferenciação pressupõem limite, kháos pode ser descrito, justificadamente, como sem limites, tendo-se em mente que "ilimitação" nesse sentido restrito e intuitivo não é a mesma coisa que infinidade espacial. Podemos dizer, em suma, que kháos se mantém em contraste com a forma delimitada das massas cósmicas subsequentes do mesmo modo que a escuridão primordial está em contraste com a subsequente luz cosmogônica. (Tradução e transliteração próprias.)

Como apontado anteriormente, a Teogonia informa que os Titãs habitam "para lá do abismo [Kháos] penumbroso" (v. 814), o que coloca um limite na espacialidade dessa divindade-lugar. Entretanto, é possível pensar que, dentro da lógica do poema há um movimento da indefinição para a crescente definição em que o cosmo toma sua forma com o nascimento das divindades (Clay, 2003: 15), de modo que Kháos possa ter surgido como algo indefinido e tenha ganhado limites e contornos conforme o nascimento das outras divindades-lugar, assumindo suas primeiras delimitações com Terra, que surge imediatamente após Kháos, e Tártaro, o terceiro a surgir. ${ }^{35}$

\footnotetext{
35 Veja-se Mondi (1989: 10): “[...] o fato de que o kháos cosmológico, agora delimitado pelos elementos que envolvem o cosmo, possa ser visto como, ou estando em, uma fenda, não necessariamente implica que o kháos cosmogônico, que existia sozinho antes da gênese de qualquer outra entidade, devesse ou pudesse ser assim visto." (tradução e transliteração próprias). Werner (2013: 12) define Kháos como "um espaço vazio cuja delimitação primeira surge na sequência, Terra".
}

Heródoto, Unifesp, Guarulhos, v.5, n.2 - 2020.2. p. 48-70.

DOI: $10.34024 /$ herodoto.2020.v5.12833 
A ausência de delimitação também é assumida por Clay (2003: 15-16), para quem kháos não parece ser uma "confusão de matéria sem diferenciação, mas sua negação, um vazio sem características". Concordo, entretanto, com Podbielski (1986: 255): “[...] Conceber Caos seja enquanto um espaço vazio ou, como deseja H. Fränkel, enquanto 'Nichtsein' ('não ser') contradiz o princípio mesmo de todo o devir, ainda mais porque, para nosso autor, Caos existe também no mundo atual" (tradução própria do francês).

Outra contradição é ainda notável: se ilimitado, ao ganhar delimitações com o nascimento de Terra e Tártaro, o kháos hesiódico perderia sua característica essencial, contradizendo o fundamento da Teogonia de que todo ser existe em razão daquilo que o constitui. Kháos pode ser ilimitado apenas no sentido de que não possui uma essência corpórea, substancial ou tangível, como Terra possui, conforme explicitado no momento mesmo de seu surgimento ao ser chamada "largo-peito" (117). Essa ausência de substância é indicada em sua progênie, e continua a sê-lo com os descendentes da Noite, a quem esta dá origem sozinha, do mesmo modo que foi gerada por Kháos (veja-se adiante). Entretanto, a falta de substancialidade não é a única característica que pode ser notada em Kháos e sua linhagem. Há uma que é de fato declarada no poema e tem sido negligenciada na maioria dos esforços interpretativos em favor do que penso serem interpretações demasiado elaboradas em termos filosóficos. Kháos é chamado zopherós ("escuro") no poema e origina os irmãos Érebo e Noite, a escuridão infra e supraterrânea respectivamente. Além disso, como uma espécie de escuridão primordial, Kháos não perderia sua raison d'être no poema, como ocorre quando é interpretado como o "ilimitado", uma perda que não ocorre a nenhuma outra entidade na Teogonia e seria uma contradição à lógica do próprio poema.

Ao observar o catálogo de descendentes da Noite, percebe-se que são em sua maioria potências danosas ou forças obscuras às quais os humanos podem ser submetidos, à exceção das Hespérides, guardiãs das maçãs de ouro (211-232). ${ }^{36}$ Quando "unida" (migeîsa, 125, literalmente "misturada")

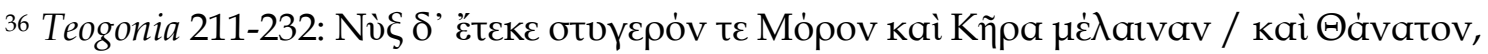

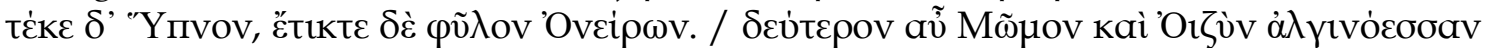

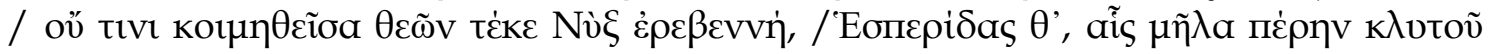

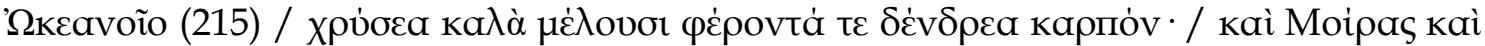

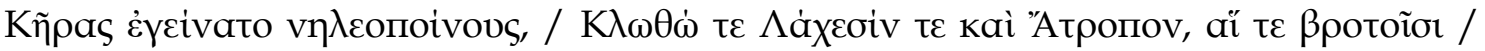

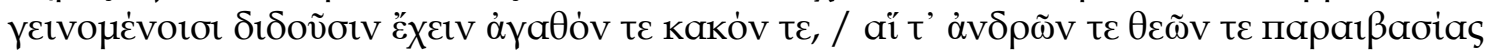

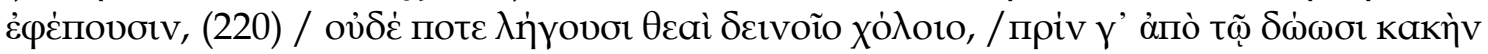

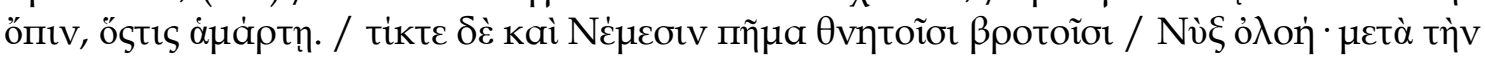

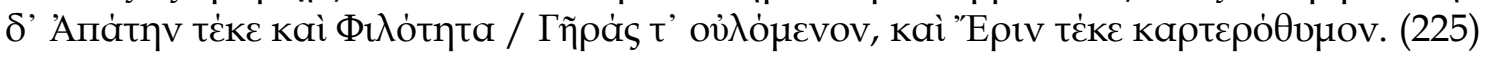

Heródoto, Unifesp, Guarulhos, v.5, n.2 - 2020.2. p. 48-70.

DOI: $10.34024 /$ herodoto.2020.v5.12833 
em amor (philótēti) a seu irmão, Noite gera Éter e Dia, contrapartes do casal originário, única união sexuada na linhagem de Kháos. Ao seguir o modo de reprodução assexuada de seu progenitor, Noite origina, ou se desdobra em, entidades que lhes são conceitualmente contíguas na concepção cosmo-teogônica do poema, e a ausência da substancialidade tem seguimento em sua progênie. Se há, de fato, na Teogonia, qualquer "agente do Kháos", a descendência da Noite ocupa tal papel de forma mais adequada ao cosmo apresentado no poema do que Tífon e são de fato conectadas ao Kháos por meio de sua linhagem.

Se as Hespérides, que cuidam das maçãs de ouro, podem parecer um elemento anômalo nessa progênie em razão de uma possível característica corpórea, seu habitat as coloca na cosmografia que diz respeito à sua progenitora. Habitando "para lá do glorioso Oceano" (215) e, sendo vizinhas das Górgonas (274-75), elas estão "no limite, rumo à noite".

Há claramente na Teogonia uma cosmografia da escuridão que merece mais atenção do que este artigo consegue lhe dedicar. Por ora, posso apenas dizer que Kháos deve estar fundamentalmente incluso nela.

\section{Conclusão}

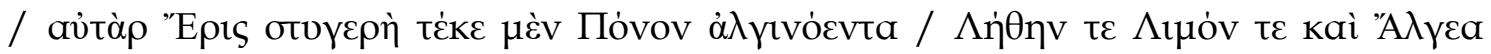

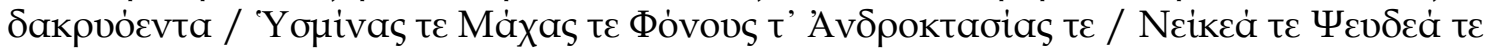

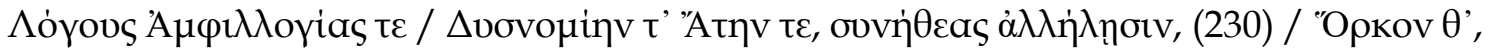

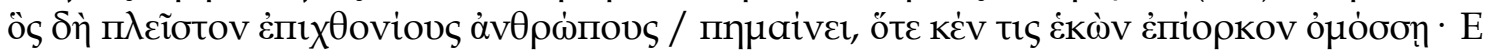
Noite pariu a medonha Sina, Perdição negra / e Morte, e pariu Sono, e pariu a tribo de Sonhos, / sem se deitar com um deus, pariu a escura Noite. / Em seguida, Pecha e aflitiva Agonia, / e Hespérides, que, para lá do glorioso Oceano, de maçãs (215) / douradas e belas cuidam e de árvores que trazem o fruto, / e Moira gerou e Perdições castigoirremissível, / Fiandeira, Sorteadora e Inflexível: aquelas aos mortais, / ao nascerem, conferem-lhes seu bem e seu mal, / estas, transgressões de varões e deuses alcançam, (220) / e as deusas nunca desistem da raiva assombrosa / até retribuir com maligna punição àquele que errar. / Também pariu Indignação, desgraça aos humanos mortais, / a ruinosa Noite; depois, pariu Farsa e Amor, / e a destrutiva Velhice, e pariu Disputa ânimo-potente. (225) / E a odiosa Disputa pariu o aflitivo Labor, / Esquecimento, Fome, Aflições lacrimosas, / Batalhas, Combates, Matanças, Carnificinas, / Brigas, Embustes, Contos, Contendas, / Má-Norma e Ruína, vizinhas recíprocas, (230) / e Juramento, ele que demais aos homens mortais / desgraça se alguém, de bom grado, falseia juramento. Sobre a Noite e seus descendentes, veja-se Ramnoux (1986: 65): “O que exatamente significa um nome de Potência? Algo de divino (tí theîn), que o homem aprende a conhecer e a nomear enfrentando a experiência. [...]" (itálico no original; tradução própria).

Heródoto, Unifesp, Guarulhos, v.5, n.2 - 2020.2. p. 48-70.

DOI: $10.34024 /$ herodoto.2020.v5.12833 
Com base na leitura das passagens da Teogonia, Kháos é uma divindadelugar primordial, como Terra e Tártaro. Sua localização na cosmografia apresentada no poema é, ao mesmo tempo, sob a Terra e para cá do Tártaro. Os filhos de Kháos, Érebo e Noite, indicam a essência da escuridão sub e supraterrânea, uma escuridão que penso ser adequadamente suposta em seu progenitor. Embora nos recônditos da Terra, mas do lado de cá do Tártaro, Kháos se mantém presente na composição do cosmo também supraterrâneo: sua essência subsiste na filha Noite e nas potências imperecíveis que descendem dela, invisíveis mas sensíveis aos mortais. Elas nunca deixarão de existir enquanto humanos houver sobre a Terra para percebê-las e por elas serem subjugados.

Apesar das etimologias propostas, o significado de seu nome ainda está por ser decifrado. Talvez a chave para sua compreensão não esteja em qualquer relação etimológica, mas num jogo sonoro de contraste e correspondência entre kháos e pháos ("luz"). Esta está sempre associada ao mundo supraterrâneo em contraste com o mundo subterrâneo: Céu não permitia a seus filhos com Terra "para a luz subir" (es pháos ouk anieske, 157), mantendo-os no "recesso da Terra" (Gaiês em keuthmốni, 158); os Centímanos também são levados "de volta à luz" (anégagon es pháos aûtis, 626) quando são resgatados de sob a Terra, e "a luz alcançaram" (es pháos aps aphíkesthe, 652) "vindos das trevas brumosas" (hypò zóphou éeróentos, v. 653). É, ainda, pertinente apontar que pháos está associado à Aurora no verso 451, o extremo oposto do ocaso, e em 755 aparece junto ao Dia na passagem em que é descrita a alternância entre Dia e Noite.

Ainda que Kháos deva ser associado ao khásma méga, um "grande abismo", é possível traçar na Teogonia mais elementos que o associam à escuridão.

\section{Referências bibliográficas}

ARRIGHETTI, G. Esiodo: Opere. Torino: Einaudi-Gallimard, 1998.

BEEKES, Robert. Etymological Dictionary of Greek. 2 vols. Leiden; Boston: Brill, 2010.

BUSSANICH, John. A Theoretical Interpretation of Hesiod's Chaos. Classical Philology, v. 78, No. 3, p. 212-219, 1983.

CHANTRAINE, Pierre. Dictionnaire Étymologique de la Langue Grecque. Histoire des Mots. Tome IV-2. Paris: Éditions Klincksieck, 1980.

CLAY, Jenny Strauss. Hesiod's Cosmos. Cambridge: Cambridge University Press, 2003. 
DENNISTON, John D. The Greek Particles. $2^{\text {nd }}$ edition. Oxford: Clarendon Press, 1954.

DÉTIENNE, Marcel; VERNANT, Jean-Pierre. Cunning Inteligence in Greek Culture and Society. Translated by Janet LLoyd. Chicago and London: University of Chicago Press, 1991.

DIAS, Domingos L. (trad., intro. e notas). Ovídio: Metamorfoses. São Paulo: Editora 34, 2017.

DUARTE, Adriane da S. (trad., intro., notas e glossário) Aristófanes: As Aves. São Paulo: Editora Hucitec, 2000.

FLACH, Hans. Glossae und Scholien zur hesiodischen Theogonie: mit Prolegomena. Leipzig: B. G. Teubner, 1876.

GRAZIOSI, Barbara; HAUBOLD, Johannes. Homer: the Resonance of Epic. London: Duckworth, 2005.

HALL, F. W.; GELDART, W. M. (eds.). Aristophanes. Aristophanes Comoediae. Vol. 2. Oxford: at the Clarendon Press, 1907.

JEBB, Richard C. (ed. with intro., notes, and prose translation). Bacchylides. The poems and fragments. Cambridge: at the University Press, 1905.

MONDI, Robert. Xaos and the Hesiodic Cosmogony. Harvard Studies in Classical Philology, v. Vol. 92, p. 1-41, 1989.

MOST, Glenn W. Two notes on Hesiod's Theogony (116-22, 426-39). In: HORNUNG, Angela; JÄKEL, Christian; and SCHUBERT, Werner (Org.). Studia Humanitatis ac Litterarum Trifolio Heidelbergensi dedicata: Festschrift für Eckhard Christmann, Wilfried Edelmaier und Rudolf Kettemann. Frankfurt am Main, Berlin, Bern, Bruxelles, New York, Oxford, Wien: Peter Lang, 2004.

(Ed. and trans.). Hesiod: Theogony, Works and Days, Testimonia (vol. 1). Cambridge, Mass.; London, Eng.: Harvard University Press, 2006. (Loeb Classical Library, 57N).

MUELLNER, Leonard. The Anger of Achilles: Mênis in Greek Epic. Ithaca and London: Cornell University Press, 1996.

PODBIELSKI, Henryk. Le Chaos et les Confins de l'Univers dans la Théogonie d'Hésiode. Les Études Classiques, v. Tome LIV, No. 3, p. 253-263, 1986. 
PUCCI, Pietro. Inno alle Muse (Esiodo, Teogonia, 1-115): Testo, Introduzione, Traduzione e Commento. Pisa, Roma: Fabrizio Serra Editore, 2007. (Filologia e Critica, 96).

RAGUSA, Giuliana (org. e trad.). Lira grega: antologia de poesia arcaica. São Paulo: Hedra, 2013.

RAMNOUX, Clémence. La Nuit et les Enfants de la Nuit dans la Tradition Grecque. Paris: Flammarion, 1986.

RICCIARDELLI, Gabriella (a cura di). Esiodo. Teogonia. Fondazione Lorenzo Valla/Mondadori, 2018.

SOLMSEN, Friedrich. Chaos and Apeiron. Studi Italiani di Filologia Classica, v. XXIV, Fascicolo 3-4, p. 235-248, 1950.

SONIK, Karen. From Hesiod's Abyss to Ovid's rudis indigestaque moles: Chaos and Cosmos in the Babylonian "Epic of Creation." In: SCURLOCK, JoAnn and BEAL, Richard H. (eds.). Creation and Chaos: A Reconsideration of Hermann Gunkel's Chaoskampf Hypothesis. pp. 1-25. Winona Lake, Indiana: Eisenbrauns, 2013.

TORRANO, Jaa. (Trad. e estudo). Hesíodo: Teogonia - A origem dos deuses. 3a. ed. São Paulo: Iluminuras, 1995.

n.54, p. 29-38, 2012.

A noção mítica de Kháos na Teogonia de Hesíodo. Ide, v. 35,

WACZIARG, Aude. Le Chaos d'Hésiode. Pallas, n. 57, p. 131-152, 2001.

WATERFIELD, Robin (trans.). Aristotle. Physics. Oxford: Oxford University Press, 2008.

WERNER, Christian. (Trad. e intro.). Hesiodo: Teogonia. São Paulo: Hedra, 2013.

. (Trad. e intro.). Homero: Ilíada. São Paulo: Ubu Editora, 2018.

(Trad. e intro.). Homero: Odisseia. São Paulo: Ubu Editora, 2018.

WEST, Martin L. Hesiod, Theogony: Edited with Prolegomena and Commentary. Oxford: Clarendon Press, 1966. 